\title{
ARTICLE \\ Objective Synoptic Weather Classification on Air Pollution during Winter Seasons in Hangzhou
}

\author{
Jiaqi Zhao ${ }^{1,2}$ Chenggang Wang ${ }^{{ }^{*}}$ \\ 1. Nanjing University of Information Science and Technology/Key Laboratory for Aerosol-Cloud-Precipitation, China \\ Meteorological Administration, Nanjing, 210044, China \\ 2. Songyuan Meteorological Bureau, Songyuan, 138005, China
}

\section{ARTICLE INFO}

Article history

Received: 19 May 2021

Accepted: 11 June 2021

Published Online: 30 July 2021

Keywords:

$\mathrm{PM}_{2.5}$

PCT

Objective weather classification

\begin{abstract}
Using the 2015-2018 Hangzhou city $\mathrm{PM}_{2.5}, \mathrm{PM}_{10}, \mathrm{SO}_{2}, \mathrm{CO}, \mathrm{NO}_{2}$ and $\mathrm{O}_{3}$ mass concentration data, ERA5 reanalysis data and ground observation data, through the PCT classification method, the objective analysis of the winter air pollution weather situation in Hangzhou was obtained. The results showed that the winter air quality concentration in Hangzhou continued to be high from 2015 to 2018, and the air pollution was the most significant. Through objective classification, it is concluded that the main weather conditions affecting the region in winter are divided into 6 types, namely high pressure control, high pressure bottom control equalizing field, L-shaped high pressure control, high pressure front control equalizing field, low pressure control, low pressure front control Equalizing field. Among them, when high pressure control, high pressure bottom control equalizing field, L high pressure control, low pressure control are affected by local sources, the impact of external sources has a greater impact on the air quality in Hangzhou, and air pollution is prone to occur; before low pressure When the pressure equalization field is controlled by the Ministry and the pressure equalization field is controlled by the high pressure front, the local wind and precipitation in Hangzhou are relatively high, which is not conducive to the accumulation of air pollutants. The probability of occurrence of air pollution is small, and air pollution is not easy to occur.
\end{abstract}

by cross-regional advection of air pollutants, horizontal and vertical mixing in the mixed layer, anthropogenic emissions, dry and wet deposition, and photochemical reactions. The external factors affecting air pollution are caused by changes in weather conditions. Changes in weather conditions ${ }^{[4-7]}$. Predecessors have done a lot of research on the impact of changes in meteorological conditions on air pollution. For example, Wu Dui et al. ${ }^{[8]}$ pointed out that the adverse effects of meteorological conditions have aggravated the

*Corresponding Author:

Chenggang Wang,

Nanjing University of Information Science and Technology/Key Laboratory for Aerosol-Cloud-Precipitation, China Meteorological Administration, Nanjing, 210044, China;

Email:sky641055@163.com 
accumulation of atmospheric pollutants in the mixed layer and increased the probability of urban smog. Zhang Renhe et al. ${ }^{[9]}$ caused most of my country's continuous According to the meteorological conditions of haze weather, unfavorable meteorological factors are the main factors leading to the occurrence of severe haze events. Therefore, categorizing the types of atmospheric circulation can better analyze the relationship between air pollution and atmospheric circulation, and play an important role in the prediction of air pollution. At present, there are two types of objective classification research. One is the source. In the last century, through subjective empirical analysis, different weather classifications were obtained. For example, Meng Yanjun et al. ${ }^{[10]}$ used empirical weather classification to conclude that when Beijing is controlled by low-pressure ground weather conditions, it is easy to cause air pollution; Zhou Ningfang et al. ${ }^{[1]}$ Through forecasting experience and synoptic principles, we classified the atmospheric circulation that affects China in winter, and concluded that three weather conditions are most likely to cause haze in China; Zhang Guolian et al. ${ }^{[12]}$ obtained the impact of winter on Shanghai by empirical classification. There are 11 types of weather conditions, 4 of which are most likely to cause $\mathrm{PM}_{10}$ pollution. Through empirical analysis, Dai Zhujun et al. ${ }^{[13]}$ found that ground cold fronts and pressure equalization fields are one of the main factors that cause severe haze in autumn and winter in Jiangsu Province. However, in practical applications, it is found that subjective weather classification depends on personal experience and understanding of professional knowledge, which is prone to deviation and difficult to verify, and gradually withdraws from mainstream research. The other is a weather classification method based on mathematical statistics. It uses meteorological data as cluster analysis as the theoretical basis, with sufficient mathematical basis and relatively small error. Among them, Ngan et al. ${ }^{[14]}$ used a two-level cluster analysis method to classify the weather situation and wind field in eastern Texas, USA, and obtained the characteristics of ozone under the weather classification; Zhang et al. ${ }^{[15]}$ analyzed by PCA Nine weather systems that affect Beijing summer air quality in 2008 were identified; Hsu et al. ${ }^{[16]}$ used a two-stage clustering method to classify weather types using surface winds and found that Taiwan is likely to cause $\mathrm{PM}_{2.5}$ under the conditions of high-pressure circulation in the mainland. The occurrence of pollution. Xu Jianming et al. ${ }^{[17]}$ used PCT weather classification to find that cold fronts and $\mathrm{H}$ weak atmospheric pressure are beneficial to the transmission of pollutants in Shanghai and are likely to cause urban pollution. Zhang Ying et al. ${ }^{[18]}$ used the PCT classification method to obtain the fractal characteristics of air pollution weather affecting North China in the winter half of the year.
Therefore, objective classification of weather conditions can reduce empirical errors. It is the development future of future weather situation classification.

Hangzhou is located at the southern foot of the Yangtze River Delta, one of the major cities in the region. Since the National Air Pollution Prevention and Control Action Plan was promulgated in 2013, the atmospheric environment has improved significantly, but winter air pollution incidents continue to occur frequently, and air pollution control still needs to be persistent. Therefore, this article will use the objective classification method to classify the different weather situation types that affect Hangzhou in winter based on the analysis of the air pollution in Hangzhou in the winter from 2015 to 2018. The occurrence characteristics of air pollution provide a reference for the air pollution prevention and control measures formulated by the Hangzhou Municipal Government.

\section{Data and Methods}

\subsection{Data Sheet}

(1) ERA5 (The fifth generation ECMWF reanalysis for the global climate and weather) provided by the European Centre for Medium-Range Weather Forecasts (ECMWF) with a $1 \mathrm{~h}$ global atmospheric reanalysis grid point Data, the time range is from January 1, 2015 to December 31,2018 , the horizontal resolution is $0.25^{\circ} \times 0.25^{\circ}$, and variables such as sea level pressure (SLP) and $10 \mathrm{~m}$ wind field (U and V) are extracted as the research Object, used for classification of objective weather situation. The boundary layer height (PBLH) is extracted to replace the mixed layer height in the calculation of atmospheric environmental capacity. (2) The hourly average $\mathrm{PM}_{2.5}$, $\mathrm{PM}_{10}, \mathrm{CO}, \mathrm{O}_{3}, \mathrm{SO}_{2}, \mathrm{NO}_{2}$ mass concentration data provided by the National Air Quality Monitoring Network (beijingair.sinaapp.com) at 17 state-controlled ambient air automatic monitoring points in Hangzhou, time range From January 1, 2015 to December 31, 2018, it was used to evaluate the environmental quality of $\mathrm{PM}_{2.5}, \mathrm{PM}_{10}, \mathrm{CO}$, $\mathrm{O}_{3}, \mathrm{SO}_{2}$, and $\mathrm{NO}_{2}$ in Hangzhou. (3) The hourly ground meteorological observation data (simultaneous period) provided by Hangzhou Meteorological Bureau including Hangzhou, Lin'an, Fuyang, Tonglu, Jiande and Chun'an, 6 national meteorological observation stations, including: Air pressure, horizontal wind direction, wind speed, temperature, precipitation, and relative humidity are used to analyze and calculate the characteristics of Hangzhou's atmospheric environmental capacity under the objective weather situation classification. 


\subsection{PCT Objective Classification Method}

There are two commonly used weather situation classification methods ${ }^{[19-20]}$, subjective classification and objective classification respectively. Compared with the objective weather situation classification, the subjective classification depends on experience, and the limitations are particularly prominent. Therefore, the objective weather situation classification has gradually developed. This paper chooses the method based on obliquely rotated principal analysis in T mode (PCT method) ${ }^{[21]}$. This method rotates the principal component analysis element of the T mode, and finally obtains the spatial distribution of the physical quantity field when the absolute value of the principal component element is the largest. Through this method, the original flow field is more accurately reflected without too much change due to the adjustment of the parting object, and the obtained space field is also relatively stable. This article adopts the weather software developed by the European COSTTION733 project, and the classification software Cost733-1.2 is downloaded from the project's official website (http://cost733.geo.uniaixgsburg.de) ${ }^{[22]}$. Extract the daily mean sea level pressure field (SLP) from January, February and December 20152018 from the ERA5 data as the typed physical quantity field, and multivariate the daily mean $10 \mathrm{~m}$ horizontal wind field $(\mathrm{U}$ and $\mathrm{V})$ during this period Oblique rotation decomposition is to expand multiple physical quantities in time and space, and then obtain a more objective and accurate atmospheric circulation pattern.

\section{Results and Discussion}

\subsection{Comparative Analysis of the Annual and Winter Mass Concentrations of Major Air Pollutants in Hangzhou}

According to the second-level limit of daily average mass concentration of six air pollutants including $\mathrm{PM}_{2.5}$, $\mathrm{PM}_{10}, \mathrm{SO}_{2}, \mathrm{CO}, \mathrm{NO}_{2}$ and $\mathrm{O}_{3}{ }^{[23]}$, the basic characteristics of air quality in Hangzhou are analyzed, and the results show that Hangzhou's $\mathrm{CO}$ and $\mathrm{SO}_{2}$ During 2015 2018 , the number of days exceeding the standard was 0 , which did not cause air pollution. During this period, the number of days of $\mathrm{O}_{3}$ exceeding the standard of air pollution was only 3 days, which had little impact on air pollution in Hangzhou, so this article will not discuss it. Comprehensive analysis shows that the main air pollutants affecting Hangzhou are $\mathrm{NO}_{2}, \mathrm{PM}_{2.5}$, and $\mathrm{PM}_{10}$. Among them, $\mathrm{PM}_{2.5}$ and $\mathrm{PM}_{10}$ affect human life and health, and are also the focus of society and air pollution academia. $\mathrm{NO}_{2}$ is an important pollution of photochemical smog.
One of the things has attracted more and more attention.

Figure 1 shows the annual and winter changes of the three air pollutants, $\mathrm{NO}_{2}, \mathrm{PM}_{10}$, and $\mathrm{PM}_{2.5}$, which mainly affect air pollution in Hangzhou. It can be seen from the figure that, except for $\mathrm{NO}_{2}$, the average mass concentration of $\mathrm{PM}_{2.5}$ and $\mathrm{PM}_{10}$ shows a decreasing trend year by year, and the mass concentration of $\mathrm{NO}_{2}$ has a rising trend. The days of air pollution caused by the daily average mass concentrations of $\mathrm{NO}_{2}, \mathrm{PM}_{10}$ and $\mathrm{PM}_{2.5}$ exceeding national standards ${ }^{[24]}$ were 167,154 , and 294 days, respectively. Among them, the number of days when pollution occurred in winter was 78,101 , and 179 days, and that occurred in winter. The number of air pollution days accounted for $47 \%, 66 \%$ and $61 \%$ of the annual pollution days, indicating that the winter has the most significant impact on the air quality of Hangzhou. In particular, the number of days of heavy pollution (31 days) in which the average daily mass concentration of $\mathrm{PM}_{2.5}$ in Hangzhou in winter exceeds the national standard ${ }^{[25]}$ accounts for $94 \%$ of the number of days (33 days) of heavy pollution in the year, which further illustrates the cause of air pollution in Hangzhou. The most important pollutant is $\mathrm{PM}_{2.5}$.

\subsection{Type Analysis of Objective Weather Situation}

In order to more accurately analyze the characteristics of atmospheric environmental capacity in different weather conditions that affect Hangzhou in winter, this study uses ERA5 to reanalyze data and adopts the PCT classification method. December) $20 \sim 45^{\circ} \mathrm{N}, 90^{\circ} \sim 130^{\circ} \mathrm{E}$ area (this area covers the main weather circulation processes affecting Hangzhou in the short term) sea level pressure (SLP) field, $10 \mathrm{~m}$ horizontal wind field (U and V) Carry out cluster analysis, which are defined as highpressure control weather situation (hereinafter referred to as H-type), high-pressure bottom control weather situation (HB-type), L-type high-pressure control weather situation (HL-type), and high-pressure front control averaging field weather situation (HF type), low pressure control weather situation (L type), low pressure front control pressure equalization field weather situation (LF type). Details are as follows:

(1) $\mathrm{H}$ type (appearing frequency is $22 \%$ )

This type of central Hangzhou area is located in the central area of cold high pressure, and is mostly controlled by the sinking airflow. The dominant wind direction is northwest-northern wind, its frequency is $57 \%$, and the average daily wind speed is $2.0 \mathrm{~m} / \mathrm{s}$. This type appeared in a total of 82 days in the classification, of which the days of $\mathrm{NO}_{2}, \mathrm{PM}_{2.5}$ and $\mathrm{PM}_{10}$ air pollution were 23 days, 33 days and 54 days respectively, and the daily average mass 

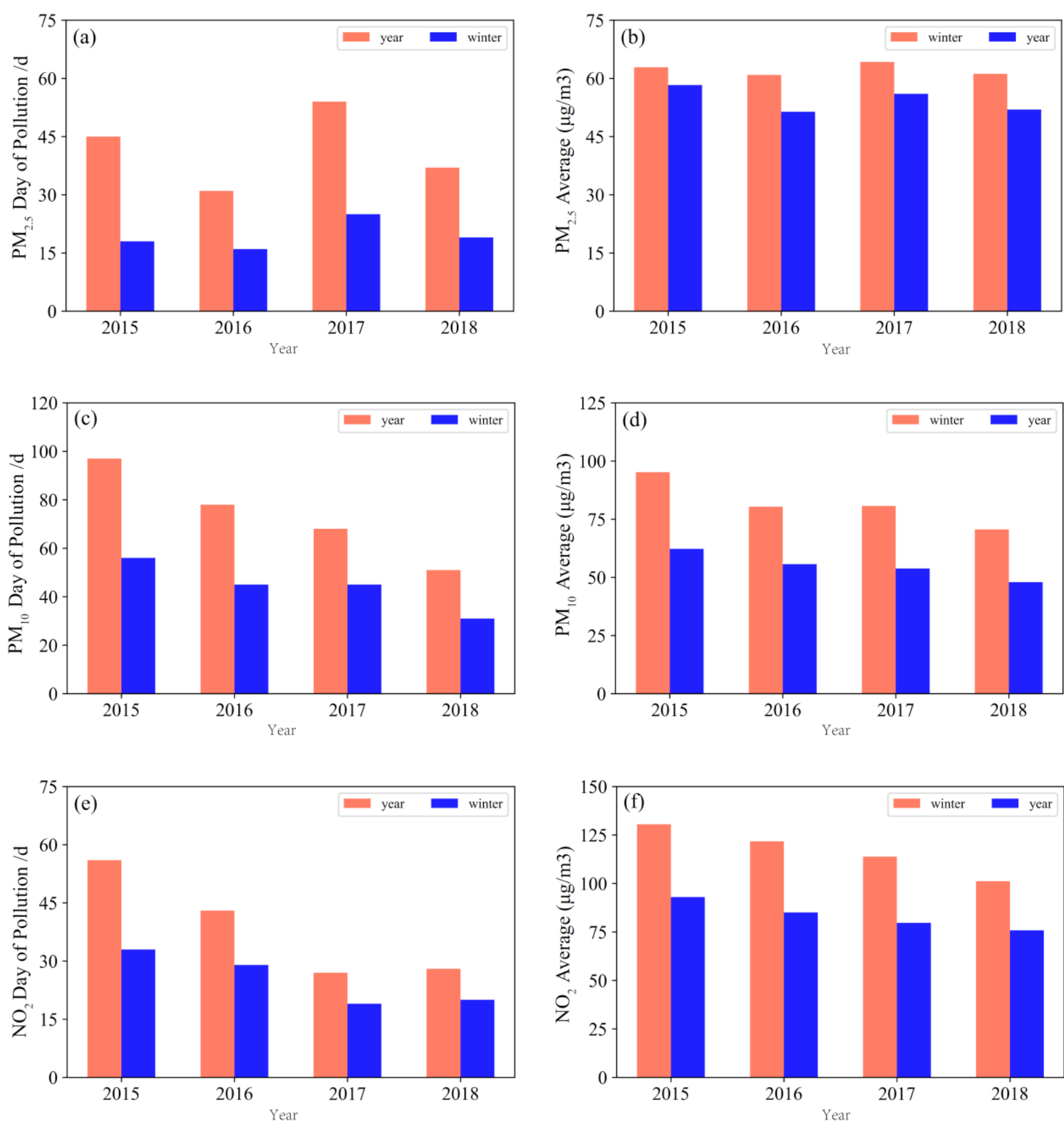

Figure 1. Comparison of the number of pollution days and corresponding mass concentrations caused by the three major air pollutants in Hangzhou from 2015 to 2018 (a. pollution days caused by $\mathrm{NO}_{2}$; b. average mass concentration of $\mathrm{NO}_{2}$; c. pollution caused by $\mathrm{PM}_{2.5}$ Number of days; d. $\mathrm{PM}_{2.5}$ average mass concentration; e. Number of days of pollution caused by $\mathrm{PM}_{10}$; f. $\mathrm{PM}_{10}$ average mass concentration)

concentrations were $70 \mu \mathrm{g} / \mathrm{m}^{3}$ and $134 \mu \mathrm{g} / \mathrm{m}^{3}$ and $93 \mu \mathrm{g} / \mathrm{m}^{3}$.

(2) HB type (appearing frequency is $11 \%$ )

This type of central Hangzhou area is at the edge of the lower part of the cold high pressure, and the main body of the high pressure center is near the north of the Huai River. Controlled by weak easterly winds and at the southern edge of the warm high pressure, the dominant wind direction is southwest-southern wind with a frequency of $41 \%$ and an average daily wind speed of $2.0 \mathrm{~m} / \mathrm{s}$. This type appeared in a total of 41 days in the classification, among which the days of $\mathrm{NO}_{2}, \mathrm{PM}_{2.5}$ and $\mathrm{PM}_{10}$ air pollution were 11 days, 11 days and 23 days respectively, and the daily average mass concentrations were $66 \mu \mathrm{g} / \mathrm{m}^{3}$ and $126 \mu \mathrm{g} / \mathrm{m}^{3}$ and $85 \mu \mathrm{g} / \mathrm{m}^{3}$. 


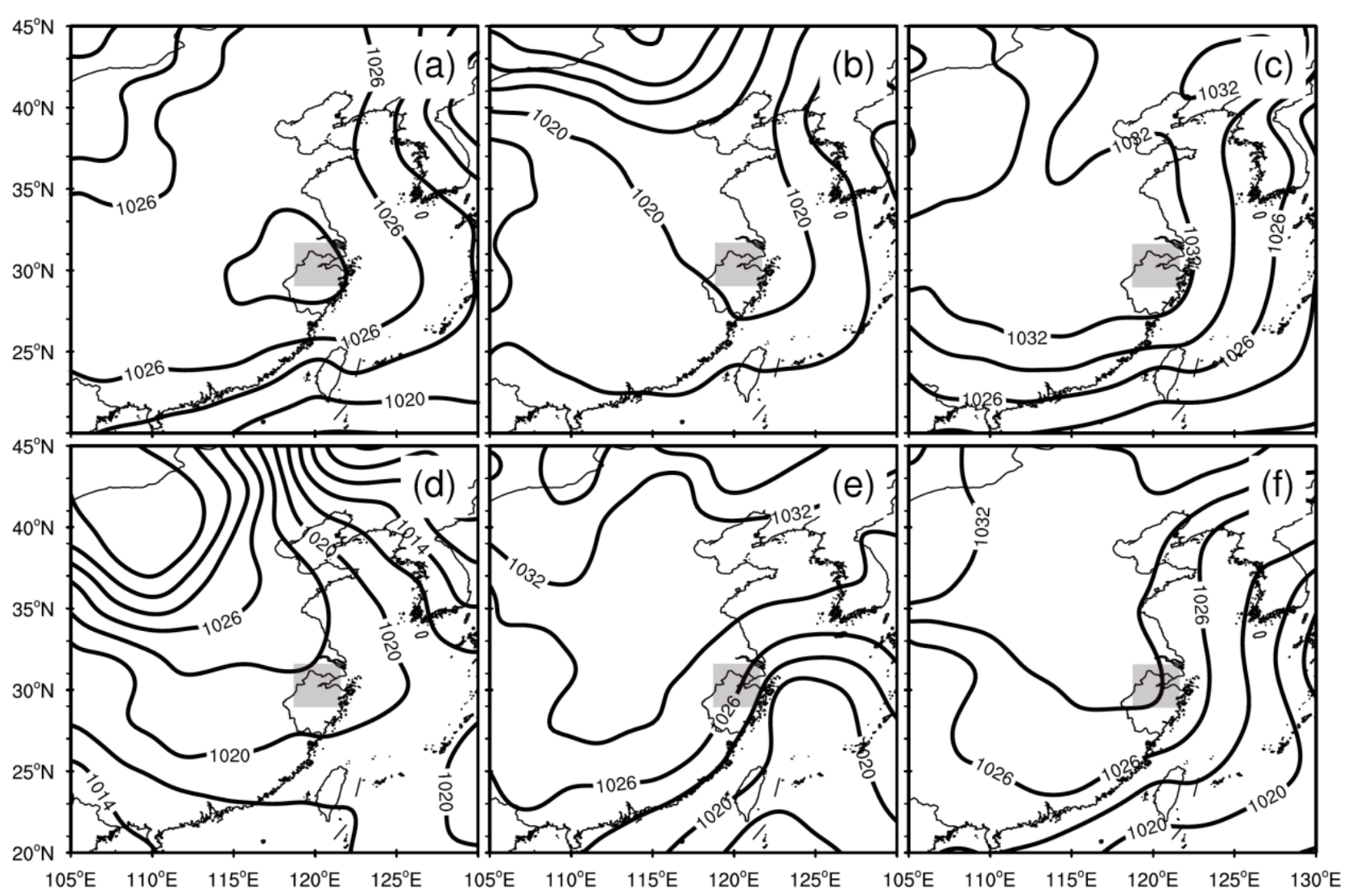

Figure 2. Classification of 6 objective weather patterns of sea level pressure and $10 \mathrm{~m}$ wind field in winter from 2015 to 2018(a). High pressure control(b). High pressure bottom control(c). L-type high pressure control(d). High pressure front control(e). Low pressure control(f). Low pressure front control

(3) HL type (appearing frequency is $15 \%$ )

In this type, the city of Hangzhou is located in the front area of the cold high pressure, which is mostly similar to the $\mathrm{L}$ shape. The main body of the high pressure center extends from the northwest-Hetao to the middle and lower reaches of the Yangtze River. The dominant wind direction is northeast-northern wind, with a frequency of $43 \%$, and an average daily wind speed of $2.1 \mathrm{~m} / \mathrm{s}$. This type appeared in a total of 53 days in the classification, among which the number of days with $\mathrm{NO}_{2}, \mathrm{PM}_{2.5}$ and $\mathrm{PM}_{10}$ air pollution were 15 days, 16 days and 21 days respectively, and the daily average mass concentrations were $58 \mu \mathrm{g} / \mathrm{m}^{3}$ and $120 \mu \mathrm{g} / \mathrm{m}^{3}$ and $84 \mu \mathrm{g} / \mathrm{m}^{3}$.

(4) HF type (appearing frequency is $24 \%$ )

This type of middle-Hangzhou city is located close to the front area of the cold high pressure. The high pressure center is mostly located in the key areas of the cold wave from Mongolia to Inner Mongolia. The dominant wind direction is northwest-northern wind, with a frequency of $69 \%$ and an average daily wind speed of $2.4 \mathrm{~m} / \mathrm{s}$. This type appeared in 86 days in the classification, among which the number of days with $\mathrm{NO}_{2}, \mathrm{PM}_{2.5}$ and $\mathrm{PM}_{10}$ air pollution were 7 days, 10 days and 31 days, and its daily average mass concentration was $55 \mu \mathrm{g} / \mathrm{m}^{3}, 96 \mu \mathrm{g} / \mathrm{m}^{3}$ and $67 \mu \mathrm{g} / \mathrm{m}^{3}$.

(5) L type (occurrence frequency is $8 \%$ )

This type of middle Hangzhou city is located in a low-pressure control area, and the affected systems are mostly transit low-pressure troughs, inverted troughs, and stationary fronts. The dominant wind direction is northwest-northeast wind with a frequency of $54 \%$ and an average daily wind speed of $1.8 \mathrm{~m} / \mathrm{s}$. This type appeared in 28 days in the classification, among which the number of days with $\mathrm{NO}_{2}, \mathrm{PM}_{2.5}$ and $\mathrm{PM}_{10}$ air pollution were 18 days, 19 days and 25 days, and its daily average mass concentration was $88 \mu \mathrm{g} / \mathrm{m}^{3}, 174 \mu \mathrm{g} / \mathrm{m}^{3}$ and $118 \mu \mathrm{g} / \mathrm{m}^{3}$.

(6) LF type (appearing frequency is $20 \%$ )

In this type, Hangzhou is located at the front edge of the low-pressure center; cold advection passes through the high altitude, bringing in the cold air mass in North China, and is affected by the weakly cold air "back flowing" from the East China Sea. The highest frequency of occurrence is northwest-northern wind. , The frequency of occurrence is $72 \%$, and the average daily wind speed is $2.4 \mathrm{~m} / \mathrm{s}$. This 
type appeared in a total of 71 days in the classification, of which the days of $\mathrm{NO}_{2}, \mathrm{PM}_{2.5}$ and $\mathrm{PM}_{10}$ air pollution were 4 days, 12 days and 25 days, and the daily average mass concentrations were $54 \mu \mathrm{g} / \mathrm{m}^{3}, 93 \mu \mathrm{g} / \mathrm{m}^{3}$ and $69 \mu \mathrm{g} / \mathrm{m}^{3}$.

Analyzing 6 types of weather situation, we can see that the weather situation that mainly affects Hangzhou in the winter of 2015-2018 is the high-pressure front control equalizing field, which is also consistent with the work of the predecessors ${ }^{[26-27]}$.

\subsection{Discussion on the Impact of Meteorological Elements on Air Pollution under the Objective Weather Classification in Hangzhou in Winter}

Changes in weather conditions such as wind speed, temperature, precipitation and humidity are the main factors that determine the formation of air pollution. Table 1 shows the statistical analysis and comparison of meteorological elements and the average mass concentration of $\mathrm{PM}_{2.5}, \mathrm{PM}_{10}$ and $\mathrm{NO}_{2}$ under different weather conditions. From the table, it can be seen that the lowest average temperature in Hangzhou during the winter of 2015-2018 under LF type control was $4.4^{\circ} \mathrm{C}$, and the winter during the four years The lowest temperature also appears under the control of LF type, which is $-5^{\circ} \mathrm{C}$. Under other weather types, the winter temperature in Hangzhou is relatively high, at $6-10^{\circ} \mathrm{C}$; the average daily wind speed is the second highest, 2.3 $\mathrm{m} / \mathrm{s}$, The average mass concentrations of $\mathrm{PM}_{2.5}, \mathrm{PM}_{10}$, and $\mathrm{NO}_{2}$ are the lowest, $69 \mu \mathrm{g} / \mathrm{m}^{3}, 93 \mu \mathrm{g} / \mathrm{m}^{3}, 54 \mu \mathrm{g} / \mathrm{m}^{3}$, respectively, indicating that Hangzhou is affected by cold low pressure in winter, and the surface wind speed is relatively high, which is beneficial to air pollution. The vertical and horizontal diffusion of air pollutants, coupled with the influence of cold air, negative changes in temperature, and more precipitation, have obvious moisture removal effects of air pollutants, so the pollutant concentration is the lowest. Under HF type control, due to the impact of weak cold air moving eastward and southward, the average daily wind speed in Hangzhou is the highest at $2.4 \mathrm{~m} / \mathrm{s}$. The cold wind gradient is large, which is conducive to the wet removal of pollutants. Therefore, $\mathrm{PM}_{2.5}, \mathrm{PM}_{10}$ The mass concentration of $\mathrm{NO}_{2}$ and $\mathrm{NO}_{2}$ pollutants is also relatively low, followed by 67 $\mu \mathrm{g} / \mathrm{m}^{3}, 96 \mu \mathrm{g} / \mathrm{m}^{3}, 55 \mu \mathrm{g} / \mathrm{m}^{3}$; while in H-type and LF-type control, the average daily wind speed is relatively small, and the atmosphere The vertical and horizontal diffusion capacity of pollutants is weak, the local relative humidity gradually decreases, and the temperature gradually rises under the influence of solar radiation. The overall mixing layer is relatively stable, which is conducive to the accumulation of atmospheric pollutants. Therefore, the mass concentration of air pollutants is relatively High; the HL type control is similar to the H and LF type control, but due to the high precipitation process in Hangzhou under this type, the humidity is relatively high, and the mixed layer is prone to temperature inversion. In addition, the humidity is high, and the pollutant particles will absorb moisture and increase. Air pollution is generated; while Hangzhou is under the control of L-shaped weather situation, because its daily average wind power is the smallest, $1.8 \mathrm{~m} / \mathrm{s}$, the horizontal diffusion ability is the worst, and under the L-shaped control, there is a lot of precipitation and the solar radiation is weak. The mixed layer does not develop vigorously. The lower mixed layer is conducive to the accumulation of atmospheric pollutants and is not conducive to diffusion, so air pollution is most likely to form. Among them, the average mass concentration of $\mathrm{PM}_{2.5}, \mathrm{PM}_{10}$ and $\mathrm{NO}_{2}$ is the highest, respectively $118 \mu \mathrm{g} / \mathrm{m}^{3}, 174 \mu \mathrm{g} / \mathrm{m}^{3}, 88 \mu \mathrm{g} / \mathrm{m}^{3}$, all exceed the national air quality level II standard. Therefore, changes in meteorological conditions under different weather conditions restrict the occurrence, development and extinction of air pollution in Hangzhou.

Table 1. Statistical analysis of meteorological elements and average mass concentrations of $\mathrm{PM}_{2.5}, \mathrm{PM}_{10}$ and $\mathrm{NO}_{2}$ under different weather conditions

\begin{tabular}{|c|c|c|c|c|c|c|}
\hline & H Type & $\begin{array}{c}\text { HB } \\
\text { Type }\end{array}$ & HL Type & $\begin{array}{c}\text { HF } \\
\text { Type }\end{array}$ & L Type & LF Type \\
\hline $\begin{array}{c}\text { Average } \\
\text { Temperature } \\
\left({ }^{\circ} \mathrm{C}\right)\end{array}$ & 6.2 & 9.4 & 8.9 & 6.9 & 8.7 & 4.4 \\
\hline $\begin{array}{c}\text { Average } \\
\text { relative } \\
\text { humidity (\%) }\end{array}$ & 63 & 61 & 78 & 72 & 71 & 73 \\
\hline $\begin{array}{c}\text { Average } \\
\text { precipitation } \\
(\mathrm{mm})\end{array}$ & 2.7 & 2.4 & 8.1 & 5.9 & 7.3 & 6.9 \\
\hline $\begin{array}{c}\text { Average } \\
\text { precipitation } \\
(\mathrm{m} / \mathrm{s})\end{array}$ & 2.0 & 2.0 & 2.1 & 2.4 & 1.8 & 2.3 \\
\hline
\end{tabular}

3.4 Discuss the Analysis of Air Pollution Characteristics under the Objective Weather Classification in Winter of Hangzhou

\subsubsection{Statistical Analysis of $\mathrm{PM}_{2.5}, \mathrm{PM}_{10}$ and $\mathrm{NO}_{2}$ Air Pollution under Objective Weather Classification in Hangzhou in Winter}

Cluster analysis is performed on the sea level pressure (SLP) field and the $10 \mathrm{~m}$ horizontal wind field (U and V) in the main weather circulation process in Hangzhou, and Table 2 is defined as $\mathrm{PM}_{2.5}$ and $\mathrm{PM}_{10}$ under six 
Table 2. Frequency of $\mathrm{PM}_{2.5}, \mathrm{PM}_{10}$, and $\mathrm{NO}_{2}$ air pollution days and clean days under the 6 weather types

\begin{tabular}{|c|c|c|c|c|c|c|c|}
\hline \multirow{3}{*}{ Pollutants } & Pollution level & H Type & HB Type & HL Type & HF Type & L Type & LF Type \\
\hline \multirow{3}{*}{$\mathrm{PM}_{2.5}$} & Heavy pollution & $8 \%$ & $17 \%-$ & $17 \%$ & $3 \%$ & $18 \%$ & $4 \%$ \\
\cline { 2 - 8 } & Moderately polluted & $15 \%$ & $7 \%$ & $6 \%$ & $5 \%$ & $32 \%$ & $11 \%$ \\
\cline { 2 - 8 } & Light pollution & $43 \%$ & $39 \%$ & $17 \%$ & $28 \%$ & $40 \%$ & $20 \%$ \\
\hline \multirow{3}{*}{$\mathrm{PM}_{10}$} & Clean day & $34 \%$ & $37 \%$ & $60 \%$ & $64 \%$ & $10 \%$ & $65 \%$ \\
\cline { 2 - 8 } & Meavy pollution & 0 & 0 & 0 & 0 & $4 \%$ & 0 \\
\cline { 2 - 8 } & Light pollution & $40 \%$ & $27 \%$ & $23 \%$ & $12 \%$ & $64 \%$ & $17 \%$ \\
\hline \multirow{3}{*}{$\mathrm{NO}_{2}$} & Clean day & $60 \%$ & $73 \%$ & $69 \%$ & $88 \%$ & $32 \%$ & $83 \%$ \\
\cline { 2 - 8 } & Light pollution & $28 \%$ & $27 \%$ & $28 \%$ & $8 \%$ & $64 \%$ & $6 \%$ \\
\hline
\end{tabular}

weather types. Figure 3 shows the frequency and average mass concentration distribution of $\mathrm{PM}_{2.5}, \mathrm{PM}_{10}$ and $\mathrm{NO}_{2}$ polluted days under different weather conditions.

As shown in Table 2 and Figure 3, the three main pollutants $\left(\mathrm{PM}_{2.5,} \mathrm{PM}_{10}\right.$, and $\left.\mathrm{NO}_{2}\right)$ that affect air pollution in Hangzhou are roughly the same according to the frequency of air pollution days, and the cumulative frequency of $\mathrm{PM}_{2.5}$ air pollution days is in order. From high to low, they are L, H, HB, HL, HF, and LF; the cumulative frequency of $\mathrm{PM}_{10}$ air pollution days is $\mathrm{L}$, $\mathrm{H}, \mathrm{HL}, \mathrm{HB}, \mathrm{LF}$, and $\mathrm{HF}$ from high to low; and $\mathrm{NO}_{2}$ air The cumulative frequency of pollution days from high to low is $\mathrm{L}, \mathrm{H}, \mathrm{HL}, \mathrm{HB}, \mathrm{HF}$ and LF respectively. Through comparison, it can be seen that the three pollutants $\mathrm{PM}_{2.5}$, $\mathrm{PM}_{10}$ and $\mathrm{NO}_{2}$ that affect Hangzhou's winter air pollution correspond to L-type weather types with the highest frequency of air pollution occurrences, with frequencies of $89 \%, 68 \%$, and $64 \%$, respectively. The average mass concentrations of $\mathrm{PM}_{2.5}, \mathrm{PM}_{10}$ and $\mathrm{NO}_{2}$ are $118 \mu \mathrm{g} / \mathrm{m}^{3}$, $174 \mu \mathrm{g} / \mathrm{m}^{3}$ and $88 \mu \mathrm{g} / \mathrm{m}^{3}$, which all exceed the national secondary standards ${ }^{[29]}$, indicating that Hangzhou is in L Type $\mathrm{H}$ is the most prone to air pollution; the second is $\mathrm{H}$ type. The daily frequency of $\mathrm{PM}_{2.5}, \mathrm{PM}_{10}$ and $\mathrm{NO}_{2}$ air pollution is $66 \%, 40 \%$ and $28 \%$, and the average mass concentration is $93 \mu \mathrm{g} / \mathrm{m}^{3}, 134 \mu \mathrm{g} / \mathrm{m}^{3}$ and $70 \mu \mathrm{g} / \mathrm{m}^{3}$, of which the daily average mass concentrations of $\mathrm{PM}_{10}$ and $\mathrm{NO}_{2}$ are lower than the national secondary standards ${ }^{[28]}$. The weather types with the lowest occurrence frequency of air pollution are HF and LF. The daily frequency of $\mathrm{PM}_{2.5}, \mathrm{PM}_{10}$ and $\mathrm{NO}_{2}$ air pollution is $36 \%, 12 \%, 8 \%$ and $25 \%, 17 \%, 6 \%$, and the average The mass concentrations in order are $67 \mu \mathrm{g} / \mathrm{m}^{3}, 96 \mu \mathrm{g} / \mathrm{m}^{3}, 55 \mu \mathrm{g} / \mathrm{m}^{3}, 69 \mu \mathrm{g} / \mathrm{m}^{3}$, $93 \mu \mathrm{g} / \mathrm{m}^{3}, 54 \mu \mathrm{g} / \mathrm{m}^{3}$, which affect Hangzhou City under different weather conditions. Except for the two pollutants of air pollution $\left(\mathrm{PM}_{10}\right.$ and $\left.\mathrm{NO}_{2}\right)$, the average mass concentration exceeds the national second-level standard under the L-type, and the corresponding average mass concentration under the other five weather conditions does not exceed the national second-level air quality For $\mathrm{PM}_{2.5}$, it shows that the average mass concentration of Hangzhou in winter under the control of the four weather conditions of $\mathrm{L}, \mathrm{H}, \mathrm{HB}$ and $\mathrm{HL}$ exceeds the national air quality level II standard. Statistics of the daily occurrence frequency and average mass concentration distribution of air pollution corresponding to the six weather types show that the occurrence frequency of air pollution days in Hangzhou during L, HB, H, and HL type control in winter is significantly higher than that of HF and LF type control. Especially $\mathrm{PM}_{2.5}$ is the most obvious.

According to statistics on the frequency of clean days under different weather conditions, it can be seen that in addition to the opposite conclusions from the above, it can be found that the most frequent weather conditions for $\mathrm{PM}_{2.5}, \mathrm{PM}_{10}$ and $\mathrm{NO}_{2}$ cleaning days in Hangzhou from 2015 to 2018 are HF and LF types, Under the control of $\mathrm{HF}$ and LF, the frequency of $\mathrm{PM}_{2.5}$ cleaning days is $64 \%$ and $65 \%$; the frequency of $\mathrm{PM}_{10}$ cleaning days is $88 \%$ and $83 \%$; the frequency of $\mathrm{NO}_{2}$ cleaning days is $92 \%$, 94\% And in 2015-2018, the frequency of $\mathrm{PM}_{2.5}, \mathrm{PM}_{10}$, and $\mathrm{NO}_{2}$ in the above two types of weather conditions, the frequency of clean days exceeded more than $60 \%$ of the total number of days in the corresponding weather types. It shows that Hangzhou is not prone to air pollution in winter under the control of HF and LF, and when Hangzhou is under the control of the other four different weather conditions (L, H, HB and HL), in addition to 

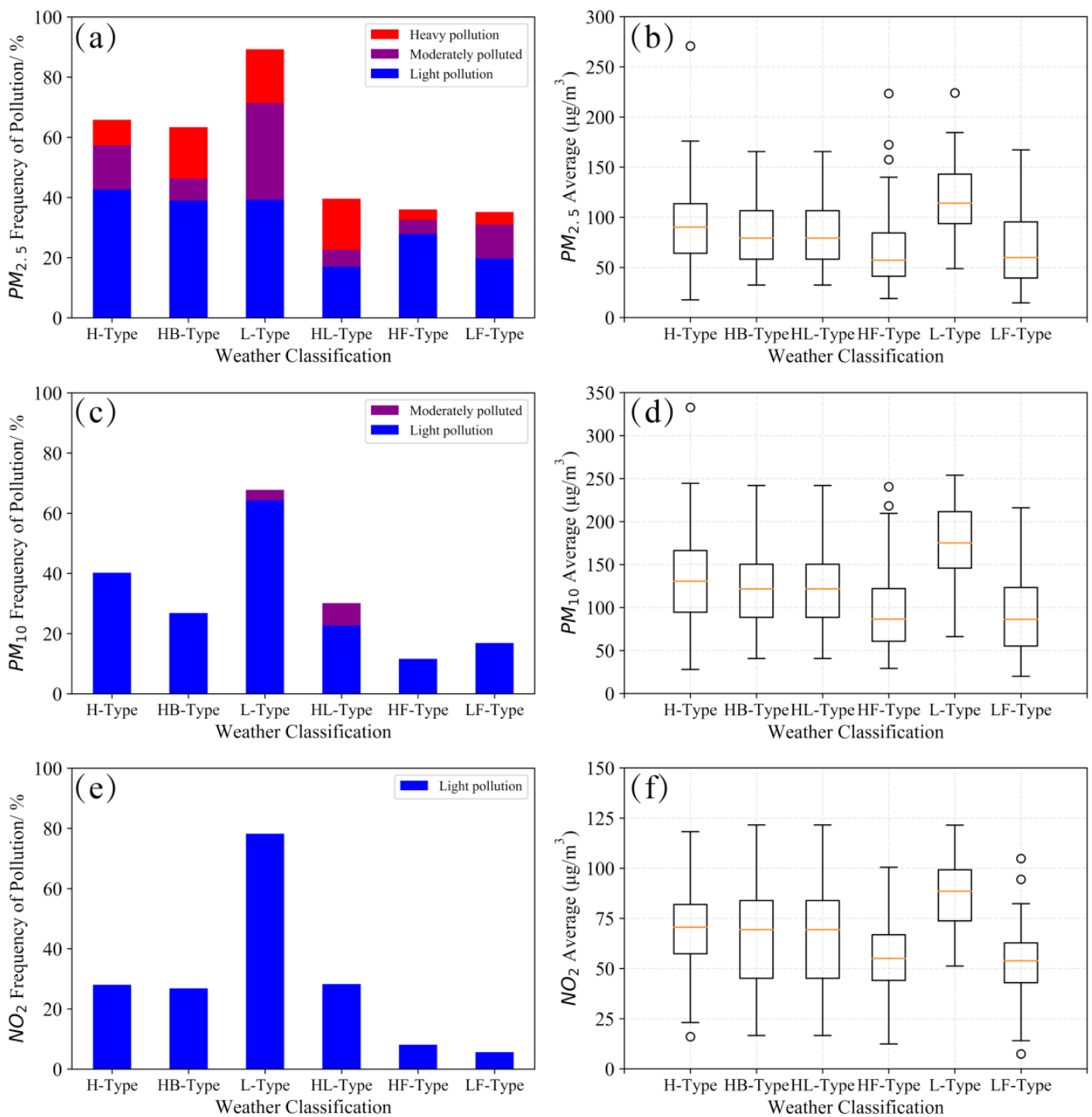

Figure 3. The occurrence frequency and average mass concentration distribution of air pollution days corresponding

to different weather types (a. $\mathrm{PM}_{2.5}$ air pollution day occurrence frequency; b. $\mathrm{PM}_{2.5}$ average mass concentration distribution; c. $\mathrm{PM}_{10}$ air pollution day occurrence frequency; d. $\mathrm{PM}_{10}$ average mass concentration distribution; e. $\mathrm{NO}_{2}$ air pollution day frequency; f. $\mathrm{NO}_{2}$ average mass concentration distribution)

$\mathrm{PM}_{2.5}, \mathrm{PM}_{10}$ and $\mathrm{NO}_{2}$ The frequency of corresponding clean days exceeded $60 \%$, which further shows that $\mathrm{PM}_{2.5}$ is the main pollutant causing air pollution in Hangzhou, followed by $\mathrm{PM}_{10}$ and $\mathrm{NO}_{2}$.

\subsubsection{Discussion on the Potential of Air Pollution under Different Weather Types in Hangzhou in Winter}

In order to explore the potential trend of air pollution caused by the three air pollutants of $\mathrm{PM}_{2.5}, \mathrm{PM}_{10}$ and $\mathrm{NO}_{2}$ under different weather types in winter of Hangzhou, based on the short-term no change in the air pollutant emission control in Hangzhou, this paper calculates
Corresponding to the 6 weather conditions under objective weather classification, the daily mass concentration of $\mathrm{PM}_{2.5}, \mathrm{PM}_{10}$, and $\mathrm{NO}_{2}$ is subtracted from the average mass concentration of the previous day to analyze and remove the factors of anthropogenic emissions, only pollution caused by changes in weather conditions Potential occurs.

It can be seen from Figure 4 that when the air pollutant difference is positive, it means that the air pollution caused by this pollutant is gradually increasing, while a negative value means that the air pollution caused by this pollutant is gradually reducing. The potential laws of air pollution in the 6 different weather types are basically the same. Among them, the air pollution is most likely to increase under the control of HB and L types, and the difference between 
the daily average mass concentrations of $\mathrm{PM}_{2.5}, \mathrm{PM}_{10}$ and $\mathrm{NO}_{2}$ and the previous day. All positive values are $2.8 \mu \mathrm{g} /$ $\mathrm{m}^{3}, 1.3 \mu \mathrm{g} / \mathrm{m}^{3}, 4.5 \mu \mathrm{g} / \mathrm{m}^{3}, 1.3 \mu \mathrm{g} / \mathrm{m}^{3}, 1.3 \mu \mathrm{g} / \mathrm{m}^{3}, 1.4 \mu \mathrm{g} / \mathrm{m}^{3}$; while LF and HF type control. The difference between the daily average mass concentration of $\mathrm{PM}_{2.5}$ and $\mathrm{PM}_{10}$ and the previous day are negative values, in order $-0.1 \mu \mathrm{g} / \mathrm{m}^{3}$, $-0.8 \mu \mathrm{g} / \mathrm{m}^{3},-0.1 \mu \mathrm{g} / \mathrm{m}^{3},-0.6 \mu \mathrm{g} / \mathrm{m}^{3}$. Although the difference of $\mathrm{NO}_{2}$ is positive, it is the minimum; combined with the above conclusions, it can be seen that when Hangzhou is controlled by $\mathrm{HB}, \mathrm{L}, \mathrm{HL}$ and $\mathrm{H}$ in winter, it is beneficial to the increase of air pollutant concentration, and air pollution occurs. The potential of, belongs to the type that is prone to polluting weather; while under the control of LF and HF, it is not conducive to the increase of the mass concentration of air pollutants and the maintenance of pollution, and it belongs to the type of weather that is not prone to pollution.
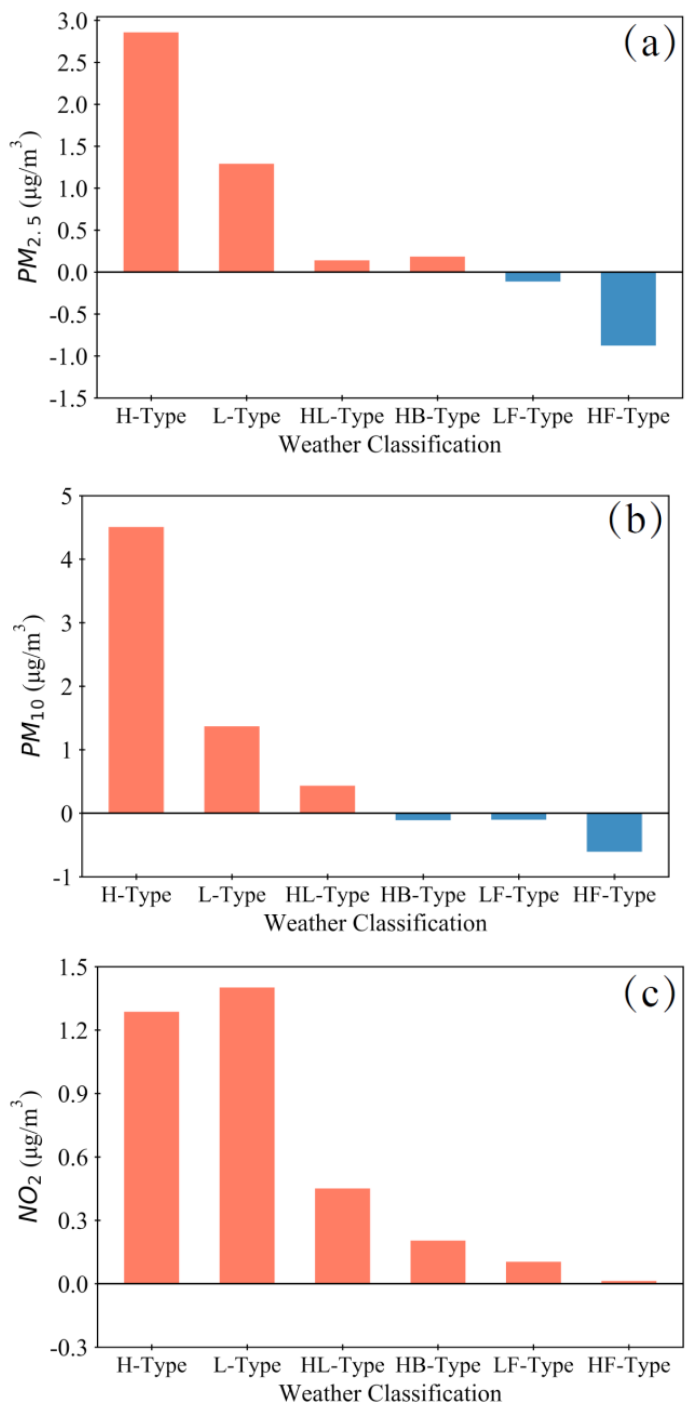

Figure 4. The difference between the daily air pollutant mass concentration and the previous day under different weather types (a.PM $\left.\mathrm{PM}_{2.5}, \mathrm{~b} . \mathrm{PM}_{10}, \mathrm{c} . \mathrm{NO}_{2}\right)$
3.5 Analysis of Potential Sources of $\mathbf{P M}_{2.5}$ Air Pollution under the Objective Weather Classification in Winter of Hangzhou

\subsubsection{Cluster Analysis of Air Pollution Trajectories under Different Weather Conditions}

Since air pollution is not only affected by local pollution sources, but also by the inter-regional transportation of pollutants in surrounding areas, there are obvious differences in pollution source areas under different weather conditions. In order to further explore the potential differences in air pollution in Hangzhou under different weather conditions, it can be seen from the above that $\mathrm{PM}_{25}$ is the most important air pollutant that affects air pollution in Hangzhou in winter. Therefore, in order to further explain the source analysis of air pollution in Hangzhou under different weather conditions, this section focuses on the process of $\mathrm{PM}_{2.5}$ air pollution instead. Using TrajStat software developed by HYSPLIT to do a backward 48-hour cluster analysis of different weather types in Hangzhou in winter, see Figure 5.

The gray in the figure is the trajectory route under all weather classifications, and the black line is the maximum 3 trajectory routes obtained by cluster analysis under each weather classification. The main air masses that affect Hangzhou under H-type control come from Inner Mongolia. Passing through Beijing-Tianjin-Hebei, Anhui, Jiangsu and other places, accounting for $47 \%$; while under the control of HB, HL, HF and LF, the main air masses affecting Hangzhou are from places passing through Hunan, Jiangxi, and southwestern Zhejiang, accounting for They are $49 \%, 41 \%, 41 \%$, and $40 \%$ respectively; while the main air mass in the L-shape is the circling through Shanghai to the eastern Zhejiang region, which affects Hangzhou, accounting for $40 \%$.

\subsubsection{Analysis of Potential Sources and Contribution Ratios of $\mathbf{P M}_{2.5}$ Pollution under Different Weather Conditions}

Through the clustering of air mass trajectories, the main air mass paths that affect Hangzhou under different weather conditions are obtained. In order to further find out the pollution sources and pollution contributions that affect Hangzhou, TrajStat software is used, and the potential source contribution factor method (WPSCF) and pollutants are used. The mass concentration weighted trajectory analysis method (WCWT) is used for analysis, as shown in Figures 6 and 7.

Among them, WPSCF analysis defines that the probability of occurrence is greater than or equal to 0.5 as 

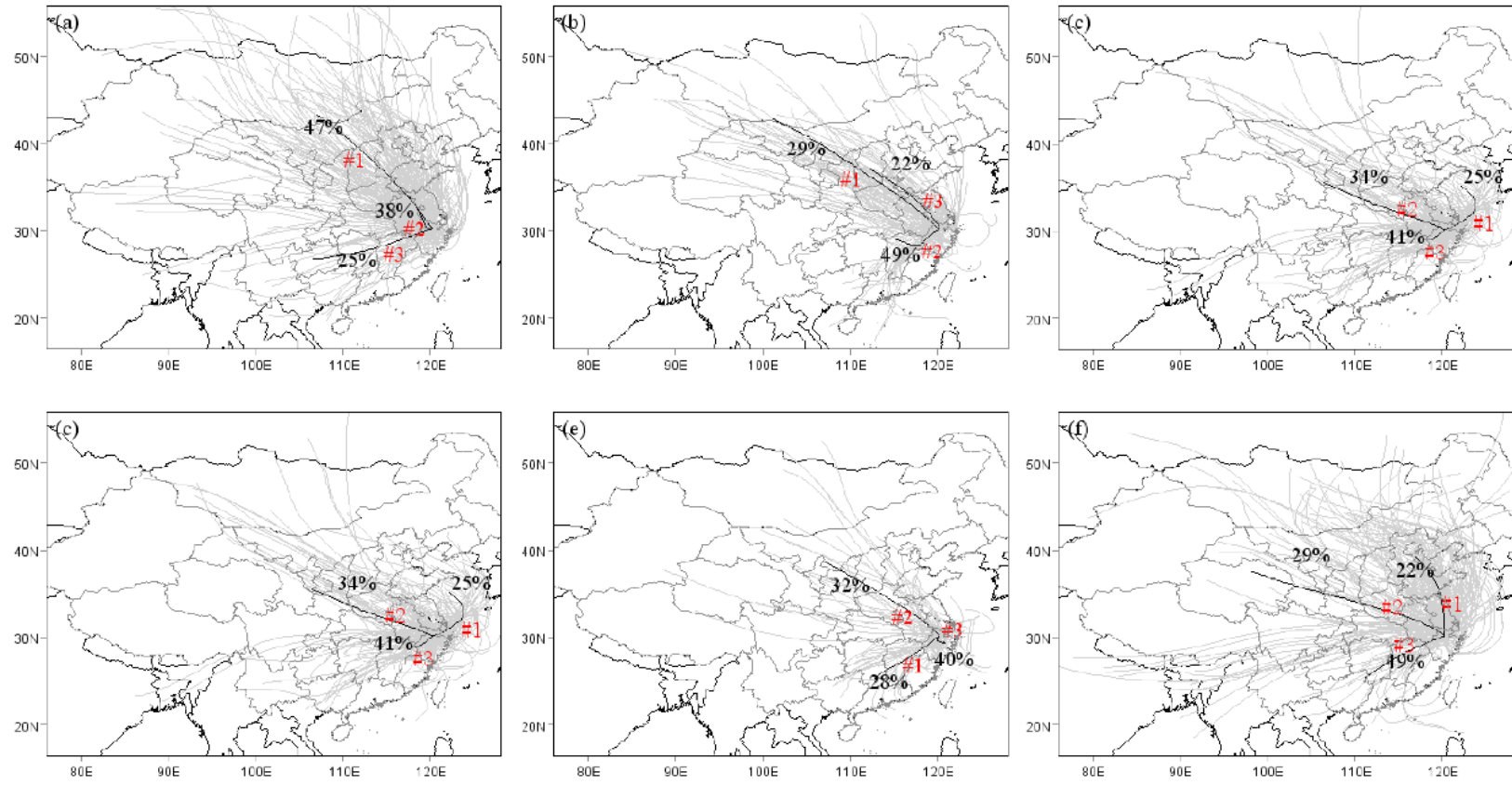

Figure 5. Cluster analysis of $\mathrm{PM}_{2.5}$ backward trajectory under different weather types (a.H type, b.HB type, c. HL type, d.HF type, e.L type, f.LF type)
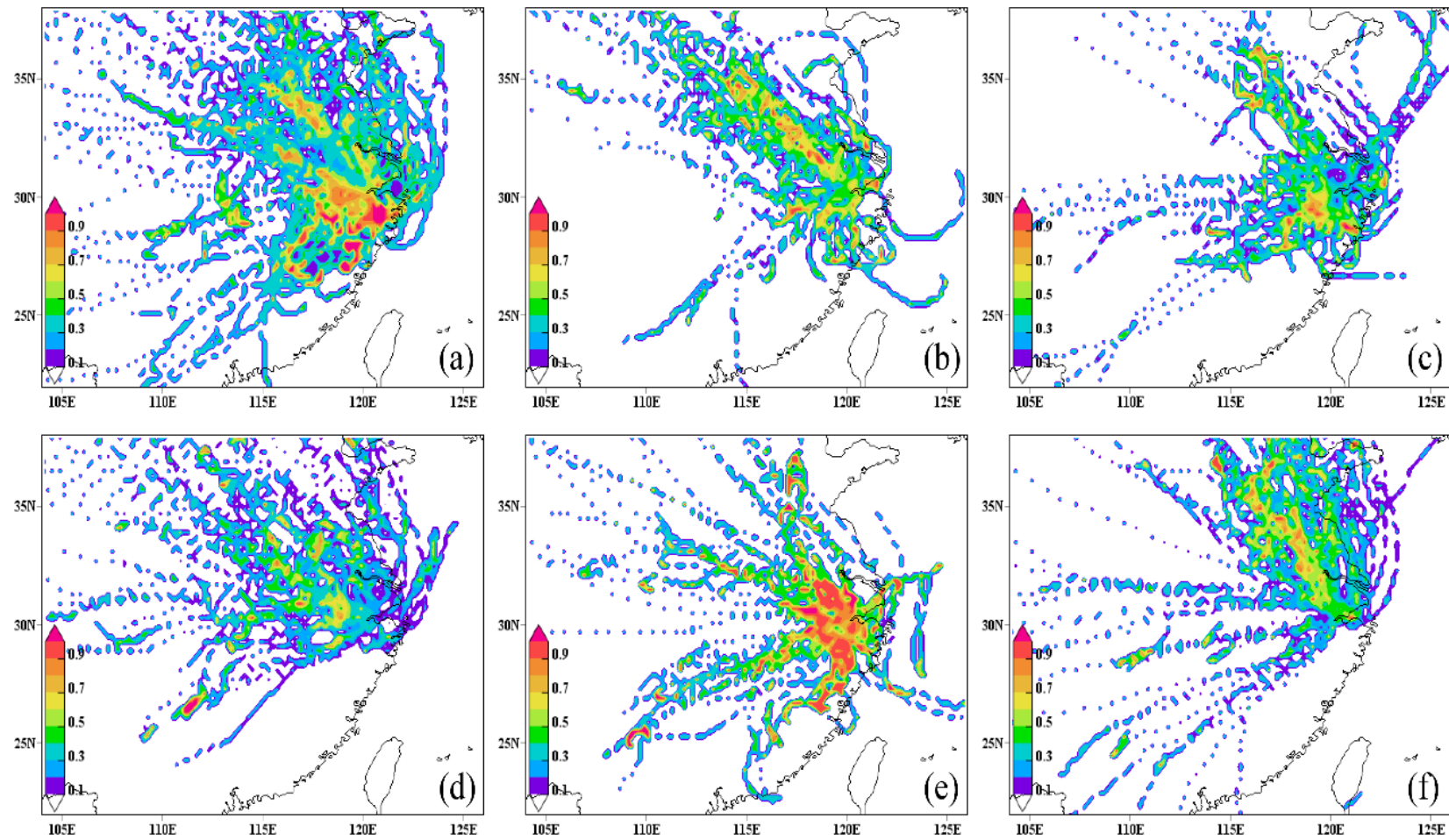

Figure 6. WPSCF analysis of $\mathrm{PM}_{2.5}$ pollution under different weather types (a.H type, b.HB type, c. HL type, d.HF type, e.L type, f.LF type, unit: \%)

the potential air pollution source affecting the area, and greater than or equal to 0.9 is the main air pollution source affecting the area. From the figure, it can be seen that the main pollution source in Hangzhou is in addition to the local area under H-type control. In Shaoxing, Jinhua,
Quzhou and other places, the probability of occurrence exceeds 0.9 , the contribution rate of $\mathrm{PM}_{2.5}$ air pollution is $100 \mu \mathrm{g} / \mathrm{m}^{3}$, while the impact of Anhui and Jiangsu also exceeds 0.7 , and the contribution rate of $\mathrm{PM}_{2.5}$ air pollution is $90 \mu \mathrm{g} / \mathrm{m}^{3}$; under $\mathrm{HB}$ type control, the main pollution 

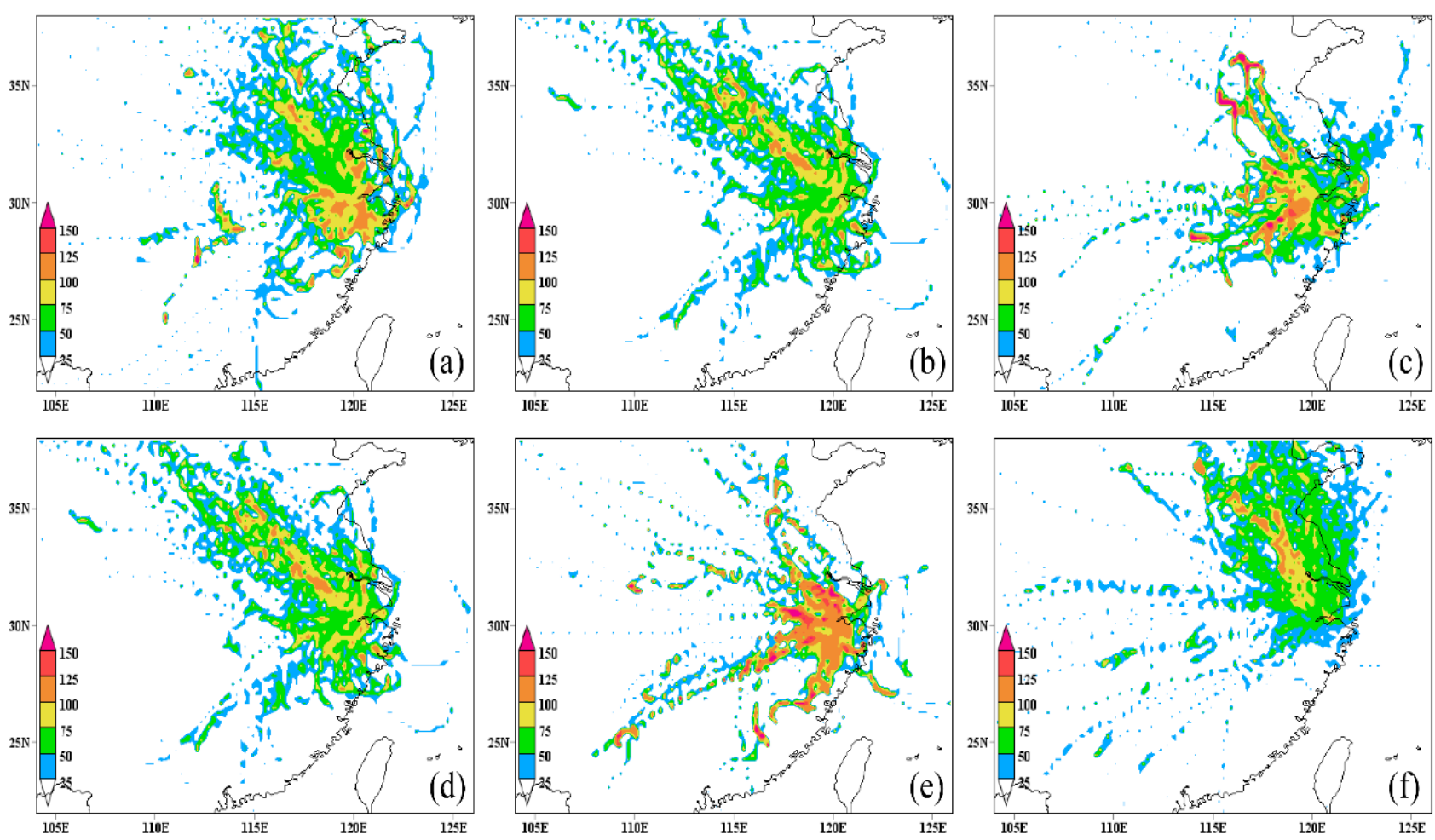

Figure 7. WCWT analysis of $\mathrm{PM}_{2.5}$ pollution under different weather types (a.H type, b.HB type, c. HL type, d.HF type, e.L type, f.LF type, unit: $\mu \mathrm{g} / \mathrm{m}^{3}$ )

sources are southern Jiangsu and central and western regions of Zhejiang, with the probability of occurrence exceeding 0.9 , followed by the local and western regions of Zhejiang, with the probability of occurrence exceeding 0.7 , and $\mathrm{PM}_{2.5}$ contributes to air pollution The air pollution rate is 110 and $90 \mu \mathrm{g} / \mathrm{m}^{3}$ respectively; under the control of HL type, the main pollution sources are the western Zhejiang region and the local region, followed by the southern Jiangsu region, with the probability of occurrence being $0.8,0.6$ and 0.5 . $\mathrm{PM}_{25}$ contributes to air pollution. The processes are 140,100 , and $90 \mu \mathrm{g} / \mathrm{m}^{3}$ respectively; under L-shaped control, the main sources are in addition to local areas, as well as central and western Zhejiang, Shanghai, southern Jiangsu, and southern Anhui. The probability of occurrence all exceeds 0.9 , $\mathrm{PM}_{2.5}$ pollution contribution degree exceeds $120 \mu \mathrm{g} / \mathrm{m}^{3}$. Under HF control, the main source of pollution is southern Anhui, followed by the local area, with the occurrence probability exceeding 0.6 and 0.5 . The contribution of $\mathrm{PM}_{2.5}$ air pollution is 95 , respectively. $75 \mu \mathrm{g} / \mathrm{m}^{3}$; under LF type control, the main pollution sources are southern Jiangsu and local areas, with the probability of occurrence being 0.6 and 0.5 , respectively. The contribution of $\mathrm{PM}_{2.5}$ air pollution exceeds 95 and $75 \mu \mathrm{g} / \mathrm{m}^{3}$. To sum up, Hangzhou is not only affected by local pollution sources, but also by the central and western regions of Zhejiang, southern Jiangsu and other places. Among them, the types of weather prone to pollution $(\mathrm{H}, \mathrm{HB}, \mathrm{HL}$ and $\mathrm{L})$ are not only affected by local sources. In addition to the impact of the source, the impact of external sources has a greater impact on the $\mathrm{PM}_{2.5}$ air quality in Hangzhou, especially in the L-shaped weather situation, it is necessary to increase the joint prevention and control of air pollution in the Yangtze River Delta to solve the $\mathrm{PM}_{2.5}$ air pollution problem. However, under the weather classification (HF and LF) that are not prone to air pollution, the impact of local pollution sources is relatively small, and the impact of external sources is relatively large. However, under the influence of these two weather conditions, the wind is relatively large and there is a lot of precipitation. It is not conducive to the accumulation of atmospheric pollutants, and the atmospheric diffusion capacity is strong, so the probability of $\mathrm{PM}_{2.5}$ air pollution is relatively small.

\section{Conclusions}

The PCT classification method was used to objectively analyze the winter weather situation in Hangzhou from 2015 to 2018, and the probability and quality of the air pollution potential source areas of the main air pollutants $\left(\mathrm{PM}_{2.5}, \mathrm{PM}_{10}\right.$ and $\left.\mathrm{NO}_{2}\right)$ affecting Hangzhou in winter Concentration analysis, the main conclusions are as follows: 
(1) According to the PCT classification method, there are 6 main weather conditions affecting Hangzhou in winter, namely HB, H, HL, L, LF and HF.

(2) Under different weather classifications, the air pollution weather patterns in Hangzhou in winter due to the influence of $\mathrm{PM}_{2.5}, \mathrm{PM}_{10}$ and $\mathrm{NO}_{2}$ three atmospheric pollutants are basically the same, and the weather classification with the highest frequency of air pollution days is L-type. The weather types with the lowest frequency are HF and LF. Statistics of the daily occurrence frequency and average mass concentration distribution of air pollution corresponding to the six weather types show that the daily occurrence frequency of air pollution in Hangzhou in winter under the control of L, HB, H and HL is significantly higher than that of the control under HF and LF. In particular, $\mathrm{PM}_{2.5}$ pollution is the most obvious.

(3) According to the potential change trend of air pollution caused by the main air pollutants $\left(\mathrm{PM}_{2.5}, \mathrm{PM}_{10}\right.$ and $\mathrm{NO}_{2}$ ) in different weather conditions in Hangzhou in winter, it can be seen that when Hangzhou is under the control of HB, L, HL and $\mathrm{H}$ Conducive to the increase of air pollutant mass concentration, it belongs to the type of polluted weather prone; while under the control of LF and HF, it is not conducive to the increase of air pollutant mass concentration and the maintenance of pollution, which belongs to the type of polluted weather that is not prone to occur.

(4) Under the six different weather classifications, Hangzhou is not only affected by local pollution sources, but also by the central and western regions of Zhejiang, southern Jiangsu and other places. Among the weather classifications that are prone to pollution (H, HB), HL and L type), in addition to local sources, the impact of external sources has a greater impact on the air quality of $\mathrm{PM}_{2.5}$ in Hangzhou, especially in the L-shaped weather situation, the joint prevention and control of air pollution in the Yangtze River Delta region should be increased. In order to solve the problem of $\mathrm{PM}_{2.5}$ air pollution, and under the weather classification (HF, LF type) that is not prone to air pollution, the impact of local pollution sources is relatively small, and the impact of external sources is greater, but under the control of HF and LF types , Hangzhou's local wind is relatively high and there is a lot of precipitation, which is not conducive to the accumulation of atmospheric pollutants. The atmospheric diffusion capacity is relatively strong, and the probability of $\mathrm{PM}_{2.5}$ pollution is relatively small.

\section{Acknowledgments}

This work was supported by the National Natural Science Foundation of China (41975011), National key
Research and Development Projects(2016YFA0602003), It also partially supported by Fuyang Government Funded Project of Hangzhou (ZJHCCGFY-0808001). We thanks for the meteorological data provided by the Hangzhou Meteorological Bureau.

\section{References}

[1] Ding A, Wang T, Xue L, et al. Transport of north China air pollution by mid-latitude cyclones: case study of aircraft measurements in summer 2007[J]. Geophys Res,2009,114, D08304.

[2] Ding A, Huang X, Fu C. Air pollution and weather interaction in East Asia[J]. In Oxford Reaserch Encyclopedias: Environmental Science,2017,1, 1-26.

[3] Otero N, Sillmann J, Schnell J, et al. Synoptic and meteorological drivers of extreme ozone concentrations over Europe. Environmental Research Letters, 2016, 11(2), 024005. https://doi.org/10.1088/1748 9326/11/2/024005.

[4] Gao Y, Liu X, Zhao C, et al. Emission controls versus meteorological conditions in determining aerosol concentrations in Beijing during the 2008 Olympic Games. Atmos. Chem. Phys. 2011,11, 12437-12451.

[5] Qu W, Arimoto R, Zhang X, et al. Spatial distribution and interannual variation of surface PM10 concentrations over eighty-six Chinese cities[J]. Atmos Chem Phys, 2010, 10:5641-5662.

[6] Pleijel H, Grundström M, Karlsson G, et al. A method to assess the inter-annual weather-dependent variability in air pollution concentration and deposition based on weather typing $[\mathrm{J}]$. Atmospheric Environment, 2016,126:200-210.

[7] Zhang Y, Ding A, Mao H, et al. Impact of synoptic weather patterns and inter-decadal climate variability on air quality in the North China Plain during 19802013[J].Atmospheric Environment,2016,124:119-128.

[8] Wu Dui, Liao Guolian, Deng Xuejiao, et al. Transport condition of surface layer under haze weather over the pearl river delta[J].Journal of Applied Meteorological Science, 2008,19(1):1-9.

[9] Zhang R H, Li Q, Zhang R N. Meteorological conditions for the persistent severe fog and haze event over eastern China in January 2013[J].Science China: Earth Sciences, 2014,57(1):26-35.

[10] Meng Yanjun, Cheng Conglan. Impact of suface synoptic situations on air pollution in Beijing area $[\mathrm{J}]$. Meteorology,2002,28(4):42-47.

[11] Zhou Ningfang, Li Feng, Rao Xiaoqin, et al. Study on haze weather in China during winter-time of 2006[J]. Meteorology,2008,34(6):81-88.

[12] Zhang Guolian, Zhen Xinrong, Tan Jianguo, et al. 
The analysis of the relationship between the air quality in shanghai and surface pressure and meteorological factos [J].Journal of Tropical Meteorology,2010,26(1) :124-128.

[13] Dai Zhujun, Liu Duanyang, Wang Hongbin, et al. The classification study of the heavy haze during autumn and winter of Jiangsu[J].Acta Meteorologica Sinica,2016,74(1) :133-148.

[14] Ngan F, Byun D. Classification of weather patterns and associated trajectories of high-ozone episodes in the Houston-Galveston-Brazoria area during the 2005/06 TexAQS-II[J]. Appl Meteorol Climatol,2011,50:485-499.

[15] Zhang J, Zhu T, Zhang Q H, et al. The impact of circulation patterns on regional transport pathways and air quality over Beijing and its surrounding[J]. Atmospheric Chemistry\& Physics\&Discussions, 2012,11(12):33465-33509.

[16] Hsu C, Cheng F. Synoptic Weather Patterns and Associated Air Pollution in Taiwan[J]. Aerosol and Air Quality Research,2019,19:1139-115.

[17] Xu J M, Chang L Y, Ma J H, et al. Objective synoptic weather classification on $\mathrm{PM}_{2.5}$ pollution during autumn and winter seasons in Shanghai[J]. Acta Scientiae Circumstantiae,2016, 36(12) :4303-4314.

[18] Zhang Y, Wang S G, Jia X W, et al. Study on an objective synoptic typing method for air pollution weather in North China during winter half year[J]. Acta Scientiae Circumstantiae,2018, 38(10):3826-3833.

[19] Compagnucci R, Richman M. Can principal component analysis provide atmospheric circulation or teleconnection patterns[J]. International Journal of Climatology, 2008, 28: 703-726.

[20] Hsu C, Cheng F. Synoptic Weather Patterns and Associated Air Pollution in Taiwan[J]. Aerosol and Air Quality Research,2019,19: 1139-115.
[21] Huth R, Beck C, Philipp A, Demuzere M, Ustrnul $\mathrm{Z}$, Cahynová M, et al. Classifications of atmospheric circulation patterns[J].Annals of the New York Academy of Sciences, 2008,1146(1), 105-152.

[22] Objective Analysis on Large-scale Circulation Type and Its Links to Precipitation over China[J].Advances in Earth Science,2018,33(4):396-403.(in Chinese)

[23] Yang Xu, Zhang Xiaoling, Kang Yanzhen, et al. Circulation weather type classification for air pollution over the Beijing-Tianjin-Hebei region during winter[J].China Environmental Science, 2017,37(9):3021-3209.

[24] Gao Y, Liu X, Zhao C, Zhang M. Emission controls versus meteorological conditions in determining aerosol concentrations in Beijing during the 2008 Olympic Games [J]. Atmos. Chem. Phys.,2011,11:1243712451.

[25] Zhang Y, Ding A, Mao H, Nie W, Zhou D, Liu L, et al. Impact of synoptic weather patterns and inter-decadal climate variability on air quality in the North China Plain during 1980-2013[J].Atmospheric Environment,2016,124:119-128.

[26] Zhang Q, Streets D G, He K, et al. NOx emission trends for China, 1995-2004: The view from the ground and the view from space[J]. Journal of Geophysical Research:Atmospheres, 2007, 112(LF2).

[27] Ashrafi K, Shafie M, Kamalan H. Estimating temporal and seasonal variation of ventilation coefficients[J]. International Journal of Environmental Research, 2010,3( 4):637-644.

[28] Lei Y, Zhang Q, He K, et al. Primary anthropogenic aerosol emission trends for China,1990-2005[J]. Atmospheric Chemistry Physics, 2011,11(3): 931-954

[29] Ambient air quality standards[S].China: GB 30952012 